\title{
Study of Informationization of Physical Education in Regular Institutions of Higher Education in Hebei Province
}

\author{
Yili, Sun \\ Jiayu, Jiang \\ Sports Department of Hebei University of Science and Technology \\ Shijiazhuang, Hebei 050018
}

\begin{abstract}
This paper takes some sports departments in higher education institutions in Hebei province as study objects, adopting the method of document literature, survey, interview and mathematical statistics to study the information infrastructure, personnel quality and the effect of the application of infomationization in those sports departments. And then we propose some strategies to promote infomationization, as follows: 1. strengthen the building of information infrastructure; 2 . raise teachers' skill of information technology; 3 . increase the use and building of teaching software; 4 . enhance the informationization study of physical education. In this way, this paper can be regarded as a reference and provide grounds for related authority to make decisions.
\end{abstract}

Keywords: Hebei regular institutions of higher education; informationization of physical education; study

Physical education is an important part in higher education and also an important way to implement education for all-round development. Informationization of physical education in higher education is a process, in which information is regarded as an essential factor in education system and information technology is widely used, to promote modernization of physical education in higher education Combining information technology with physical education can provide wider and broader space and stage for physical education, breakthrough traditional physical education model, enhance teaching efficiency, stimulate students' interest, make them actively engaged in physical education, arouse their enthusiasm to have physical training and strengthen their body. In this way, physical education can truly play its own role in higher education.

\section{Study Objects and Methods}

We adopt the method of literature materials, survey, interview and mathematical statistics to study the current situation of informationization of physical education in thirty higher education institutions in Hebei province.

\section{Discussion and Analysis}

To make an observation of the current situation of physical education informationization in Hebei higher education institutions from the aspects of information infrastructure, personnel quality and the effect of information application.

\subsection{Information Infrastructure Building}

After investigating, we find out that physical education department mainly has the following information equipments: computers, recorders, projectors, televisions, scanning machines, cameras and so on. However, because the teaching conditions are different, the most popular equipment is still recorders, and then is the computers, just for official business, with only 6 in average in each school and 0.27 per person. The other equipments are only used in conference or other activates.

Internet is an important means in informationization education. All schools use campus internet and physical education departments also have their own websites. But updating lags relatively behind, the content contains only documents and notices.

Software is the key to informationization education. What physical education departments own most is practical physical education video, then is theoretical 
education PPT. What they use most is grades management system.

\subsection{Teachers' Quality}

Physical information quality means the physical educators' ability to understand information and its features and value, and to get, analyze and use information, including information capability, concept, and morality. After observation, thanks to the 10-year qualification computer tests, over $90 \%$ of physical education teachers, who is the main part in the teaching force in Hebei, can use computers and internet proficiently. $43 \%$ teachers surf the internet more than 4 hours a day, $48 \%$ more than 1 hour a day. All of the teachers use education management system to give students grades.

The survey also shows that people who are responsible for physical education departments' websites are physical teachers rather than professional IT people, which is one of the reason why the updating of the websites lags behind.

\subsection{The application of informationization}

The application of informationization means the use of information technology and internet in physical education in higher education institutions. After investigation, we find out higher education institutions in Hebei province seldom use information technology. Where they may use it is in fitness exercises and martial art teaching, with recorders and television as the main equipments. The other teaching programs just use computers to play some teaching PPT or video in theoretical classes. $95 \%$ of the public teaching software is single tech video product, $48 \%$ of the individual teaching software is the video of sports race. The most popular teaching software is physical education management system, with $100 \%$ rate of use, then is the video of sports race, with $63 \%$ use, single tech video products, with $47 \%$, self-made teaching PPT, with only $12 \%$ rate of use. No school has its own platform to develop teaching PPTs. Only $10 \%$ have physical education resource base. $100 \%$ teachers get teaching materials from internet. $17 \%$ teachers get teaching materials from public teaching software.

As to internet, $100 \%$ of the computers physical departments own have access to internet, and $100 \%$ have their own websites. But they seldom use internet to carry out a program, even they do so, the level of the information technology they use is very low. Some functional high tech information technologies suitable for the physical education and training have not yet been used, such as the full-information system which is based on wifi technology and helpful to students' learning of skills, and the experts consultation system which is based on artificial intelligence technology and useful for students to study on their own.

\section{Result and Suggestion}

\subsection{Strengthening the Building of Information Infrastructure}

The building of information infrastructure is the basis of the development of information knowledge, ability and quality. According to our survey, higher education institutions have not yet regarded internet information as one of the major elements to build physical education playgrounds. So schools should strengthen the information hardware building in practical teaching area and consider setting up a special information platform to stimulate students' interest and learning efficiency.

We can adopt the method of combining the school investment and social finance, choosing suitable partner. In this way, we can not only save school's expenditure, but also provide good technology support and service for physical education.

\subsection{Enhancing Teachers' Information Technology Skill}

Teachers should master and apply modern information technology to improve intelligence structure, teach students to get the means to get sports and health information in modern society, and guide students to take part in physical practice actively to reach the best effect of physical education. So higher institutions should invite experts in this field according to the feature of physical information, to train teachers about how to make multimedia teaching PPTs and introduce how to use physical software, master how to use internet to look up, analyze and deal with physical information.

\subsection{Increasing the Application of Teaching Software}

The survey shows that novel and enjoyable teaching software can better stimulate students' interest to learn. However because of teachers' limited computer skill and lack of platform to use, PE teachers now can only use PPT or some video in class. So increasing the application of teaching software directly concerns about 
the result of physical teaching. Teachers should communicate with students more, understand their ideas On one hand, schools can purchase some new software, and on the other hand, they can make full use of brain and human resource to develop software by teachers themselves or even by students. Thus teaching software can be better directed to benefit physical education and gain better teaching result.

\subsection{Enhancing the Informationization Study of PE}

\section{Practical Class}

Sports have their own features. PE class pay much attention to physical exercise, so practical class is the main part. Though physical education informationization has made some progress, the fact is that only in the beginning and end of the semester, students can have the chance to get informationization knowledge, while in the whole process of teaching, teachers just use traditional equipments and methods, which is explanation, demonstration and students exercises, but seldom use modern equipments and methods. Today, the tie between electronics technology and human life becomes increasingly close. How to combine electronics technology with physical education has a direct bear on the quality of physical education, and the enhancement of students physical quality. So schools should keep up with times to enhance informationization study of physical practical class. While making full use of the traditional methods and equipments, they should explore informationization road that is suitable to the teaching feature of physical practical classes in higher institutions, change its current situation, and promote the development of informationization of physical education.

\section{References}

[1]Cao, Yongqing \& Wang,Xinwu \& Wang, Yan. Study and Discussion of the Informationization Website and Its Use in Regular Institutions of Higher Education. [J] .Hebei University of Engineering Academic Journal, 2009，(2): 99-100

[2]Wei, Yadong \& Guo, Ying. Using Campus Network to Build Teaching Platform for Physical Education.[J]. Beijing Sport University Academic Journal,2005，28，(12): 1696-1697

[3] Chen, Jiaqi \& Sun, Qingzhu \& Chen, Peiyou. Study on How to Cultivate and Strengthen Physical Information Quality[J]. Beijing Science,2002, 28, (3): 56-59

[4] Nan, Kai. Investigation and Development Strategy on Physical Informationization in Higer Institutions [J] . Pingding Mount Engineering Institute Academic Journal, 2008，17，(2): 89-92

[5] Chang, Dongdong. Study on Physical Informationization Management Mode in Higher Education Institutions [J]. Hubei Sports Science and Technology, 2007, 26, (5): 593-595

[6] Jiang, Rong \& Wang, Xin. Current Situation and Strategies of PE Teachers'Information Quality [J]. Sports and Science, 2002, 23, (5): 66-68

[7]Zheng, Qi \& Li, Jihui. Study Theory and Method on Modern Physical Science [M]. Beijing, People's Sports Press, 2001 